\title{
Organizational power predicts decision making quality
}

\author{
Patrícia Arriaga ${ }^{1}$, Ana Guinote ${ }^{2}, \&$ Maria Vicente Rosa ${ }^{1}$ \\ ${ }^{1}$ Iscte-Instituto Universitário de Lisboa, Cis-IUL, Lisboa, Portugal \\ 2 University College London, London, UK
}

\begin{abstract}
The aim of this study was to analyze the link between power and the quality of decision. Participants were 50 employees from an organizational company, consisting of two groups (High-Power, $\mathrm{N}=24$; Low-Power, $\mathrm{N}=26$ ) based on the organization's hierarchical power position. To evaluate the quality of the decisions, all participants performed tasks involving choice among several alternatives in two separate moments of the same day: in the morning (at the beginning of the workday) and late afternoon (at the end of the workday). Additional subjective measures (fatigue, alertness, effort) and skin conductance were obtained. Results indicated that having high power in the organization was related to making better decisions, over and above the subjective levels of fatigue, alertness, effort, and physiological arousal. No effects of time-of-day were found on the decision making. Consistent with experimental research, having power facilitated decision-making performance in an organizational context.
\end{abstract}

Keywords: Power; decision making; time-of-day; alertness; fatigue; arousal.

O poder organizacional é preditor da qualidade da tomada de decisão: 0 objetivo deste estudo foi analisar a associação entre poder e qualidade na decisão. Participaram 50 funcionários de uma empresa organizacional, divididos em dois grupos (Elevado-Poder, $\mathrm{N}=24$; Baixo-Poder, $\mathrm{N}=26$ ) em função da sua posição de poder hierárquico na organização. Para avaliar a qualidade das decisões, todos os participantes realizaram tarefas envolvendo escolhas entre alternativas em duas fases no mesmo dia: manhã (início do período de trabalho) e final de tarde (a terminar o período de trabalho). Foram recolhidos dados adicionais de medidas subjetivas (fadiga, alerta, esforço) e de atividade eletrodérmica. Os resultados indicaram que o elevado poder na organização associou-se a melhor tomada de decisão, controlando os níveis subjetivos de fadiga, alerta, esforço e ativação fisiológica. Não foram encontrados efeitos da fase do dia na tomada de decisão. Consistente com a investigação experimental, o poder facilitou o desempenho na tomada de decisão num contexto organizacional.

Palavras-chave: Poder; tomada de decisão; fase do dia; alerta; fadiga; ativação.

The position that individuals occupy in the social hierarchy affects their ability to attain their desires and thrive. While many factors directly or indirectly contribute to these social hierarchical disparities (e.g., Fiske, 2010; Monteiro, 2003), one such factor is the way people's relative power affects basic cognitive processes and the ways they pursue goals (see Guinote, 2007b, 2017). A great deal of experimental research has recently shown that having or lacking power affects how people think and act in ways that can promote (when people have power) or hinder (when people are powerless) attaining their desired outcomes. This occurs in part because a power position satisfies, and a subordinate hierarchical position thwarts basic needs for control (Fiske, 2009; Lammers et al., 2016) and a positive self-regard (Monteiro et al., 2009; Wojciszke \& Struzynska-Kujalowicz, 2007). Consequently, individuals can devote their undivided attention to the task at hand and their priorities when they have power.

In contrast, when they lack power, individuals prioritize regaining control and managing their value and identity. These findings were based on experimental research. Here we conducted a study to assess whether the relative benefits of power for cognition and decision making also occur for naturally occurring power differences in organizational settings. Specifically, we investigated whether organizational power is associated with decision making quality.

Compared to being in a low-power position, being in a high-power position may enhance performance in several social situations, such as in negotiations and job interviews (Lammers et al., 2013; Magee et al., 2007). For example, power-holders are more frequently the first to make an offer in negotiations and are more likely to obtain a better deal (Magee et al., 2007). In another study, participants randomly assigned to a powerful condition, compared to those in a control condition, completed a higher

${ }^{1}$ Correspondence address: Patrícia Arriaga, Iscte-Instituto Universitário de Lisboa, Avenida das Forças Armadas, 1649-026 Lisboa. E-mail: patricia.arriaga@iscte.pt 
proportion of correctly solved anagrams (DeWall et al., 2011). Power holders also tend to generate better arguments to make a point than powerless individuals (Weick \& Guinote, 2008). People in powerful positions pay more attention to information relevant to their goals and ignore information that is irrelevant (Guinote, 2007b; Smith \& Trope, 2006).

Similarly, women assigned to a powerful position perform better math calculations than women in a control condition (Harada et al., 2013; Van Loo \& Rydell, 2013). These results were due to better working memory, i.e., a cognitive system that temporarily holds information for further information processing and reasoning (Baddeley, 1996). Women in power also perform better on visual rotation tasks than powerless women (Nissan et al., 2015).

Prior studies have shown that power affects the speed and quality of decision making. When facing decisions between courses of action, such as choosing a holiday place, power-holders are faster than powerless individuals (Guinote, 2007b, 2017). Power holders often disengage from domains that they do not deem important (DeWall et al., 2011). Power may enhance decision-making quality, as power holders can devote their undivided attention to the task at hand. Smith et al. (2008) presented participants assigned to powerful and powerless conditions with apartments that varied in quality. Power enhanced choice under non-optimal conditions (when thinking consciously about the apartments). Experimentally induced power triggers more efficient cardiovascular responses during the completion of a difficult task (Scheepers et al., 2012), contributing to cognitive advantages during such tasks.

Power can be beneficial for task performance, especially in tasks that power holders deem important (DeWall et al., 2011). Lack of power tends to be detrimental, decreasing cognitive performance (Cai \& Guinote, 2017; Guinote, 2007a; Smith et al., 2008). When individuals are in socially disadvantaged positions, they are motivated to counteract their lack of control (Fiske \& Depret, 1996) or value (Monteiro, 2003).

Evidence suggesting that being powerless is detrimental also appears on several cognitive tasks associated with executive functions and the pursuit of goals. Powerless individuals are less capable of inhibiting task-irrelevant information in a Stroop task (Smith et al., 2008). When multitasking is necessary during dual-tasking or switching rapidly across tasks, powerless individuals are less effective, making more errors or taking more time to complete the tasks than control and powerful participants (Cai \& Guinote, 2017).

Even though lacking power impairs some cognitive functions, studies focusing on natural groups show that a subordinate position is not detrimental for all types of judgments and decisions. For example, members of low power groups, such as ethnic minorities, do not necessarily devalue the self and their social groups (Major, 1994; Monteiro, 2003). Monteiro proposed that the social comparative context (e.g., the presence of other disadvantaged group members) plays a crucial role in social judgments and the strategies adopted by members of low power groups to achieve positive distinctiveness.

One question that arises is whether power affects decision making also in naturally occurring power settings. This question is important because the decisions of power holders affect have consequences for subordinates and society. Experimentally induced power differs from naturally occurring power in important ways that could affect how people make decisions. People who occupy powerful positions may have different traits, resources, such as wealth and education, and age and gender compared to those who are powerless. For example, leaders tend to be more extroverted and dominant (Guinote \& Chen, 2018) and appear to be more intelligent and competent (Anderson \& Kilduff, 2009; Judge et al., 2004). A metaanalysis (Judge et al., 2004) showed that the relationship between leadership and intelligence is weak ( $\mathrm{r}=$ .27; Judge et al., 2004). However, appearing intelligent ( $r=.60$; Judge et al., 2004) and competent (Anderson \& Kilduff, 2009) is predictive of power affordance. Individual differences associated with factors such as these are controlled for in experimental power research. Given the disparities between naturally occurring power and temporarily afforded power, it is unknown whether power affects decision-making in natural settings. This question is addressed in the present study.

\section{The Present Research}

The present study employed a complex decision task, based on the Unconscious-Thought Theory (UTT) (Dijksterhuis, 2004), and relatively similar to that used by Smith et al. (2008). They presented participants assigned to powerful and powerless condition with many descriptions of four apartments that varied in quality. Under deliberate conscious thinking about the apartments, powerful participants made more accurate evaluations of the apartments than powerless participants. This difference was not due to distinctions in the effort deployed during the task. Under a distraction condition in which participants formed their decision after being distracted for $4 \mathrm{~min}$, both groups performed similarly and better than in the deliberate conscious thinking condition. In the present study, we evaluated decision making in a different condition that has also been used before (e.g., Abadie et al., 2013; Dijksterhuis, 2004): participants 
were asked to make decisions immediately after receiving information about the apartments. Overall, we hypothesized that employees in a position of power in the organization would make better decisions than subordinate employees.

We also examined whether this relationship between power and decision making was constant across the workday stages, specifically in the morning (at the beginning of the workday) and in the afternoon (at the end of the workday). Thus, participants performed the decision-making task twice.

Previous studies have shown that time-of-day can affect cognitive process, such as memory (e.g., Barbosa \& Albuquerque, 2008; Testu \& Clarisse, 1999), vigilance (e.g., Craig et al., 1987), and decision making (e.g., Ingram et al., 2016; Kouchaki \& Smith, 2014), with morning performance being superior to afternoon or evening performance. Thus, based on the assumption that effortful executive function, required by the complexity of the decision-making task, involves energy resources that may be depleted throughout the day, we also expected better decision-making in the morning than in the evening.

Also, we measured states of alertness, effort, fatigue, and arousal levels, because these are also related to cognitive processes (e.g., psychomotor vigilance, speed of mental operations, executive functions, and memory) that affect decision performance (e.g., Dijk et al., 1992; Fabbri et al., 2013; Wright \& Kirby, 2001). For example, alertness involves both neurophysiological arousal and sustained attention (Oken et al., 2006), both relevant for information processing. However, mental fatigue and poor sustained attention may reduce alertness and reduce performance (Taylor et al., 2018). Thus, we evaluated whether there would be differences between powerless and powerful individuals in these states, which could explain the quality of decisions. We expected that higher states of alertness and physiological arousal and lower reports of fatigue and effort would predict better decision making and potentially mediate the effect of power on decision making.

\section{METHOD}

\section{Participants}

Fifty volunteers (28 female; 22 male) aged 23-58 years $(M=39.78, S D=8.96)$ from a pharmaceutical company located in Portugal collaborated in this study. Employee's length of service in the company ranged from 3 months to 24 years and eight months ( $M=78.66$ months). Participants held high-power $(N=24)$ or low-power $(N=26)$ in the organization, based on the self-assessment of their hierarchical level (Weick \& Guinote, 2008) and number of workers under supervision (Van Dijke \& Poppe, 2006).

Most participants in high-power positions were managers $(N=14 ; 58.3 \%)$, others were leaders $(N=$ 7), or accountant, medical scientist, and lawyer in leading positions. In the low-power position, participants enacted the following roles: administrative $(N=7)$, assistants/secretaries $(N=8)$, technicians $(N=5)$, legal associates $(N=2)$, one security officer, one account receivable, one client support, and one freelancer. The majority with low-power reported having secondary school (73.3\% vs. 26.7\%), whereas most of highpower participants indicated having higher education, $57.1 \%$ (vs. $42.9 \%$ ), $\chi^{2}(1, N=50)=3.90, p=.048$. No differences between high and low-power groups were found regarding length of service in the company, $t(48)=0.82, p=.415$, although high-power participants were older $(M=42.50 ; S D=7.98)$ than low-power participants $(M=37.27, S D=9.22), t(48)=2.14, p=.038$. In addition, we also performed a physiological examination of participants of their baseline levels of blood pressure (BP), to investigate whether there would be differences between high and low power individuals in this variable that should be accounted for. Past research has also shown that electrodermal lability can be affected by BP values (Kronholm et al., 1996), therefore we screened participants for hypertension. Based on the resting values taken in the morning of the day in which the decision tasks were made, systolic BP ranged from 80 to $190 \mathrm{mmHg}(M=$ 119.6; $S D=16.9)$, while diastolic BP ranged from 50 to $100 \mathrm{mmHg}(M=69.0 ; S D=10.9)$ with no statistical differences in systolic $\mathrm{BP}, t(48)=0.49, p=.63$, although high-power participants presented higher diastolic BP $(M=7.25 ; S D=1.19)$ than low-power participants $(M=6.58 ; S D=0.90), t(48)=2.27, p=.028$. Based on the WHO-ISH criteria 1999 for classifying hypertension (systolic BP $\geq 140 \mathrm{mmHg}$ and/or diastolic BP $\geq$ $90 \mathrm{mmHg}$ ), only 5 participants in the high-power and 3 in the low-power group participants could be considered hypertense, $\chi^{2}(1, N=50)=0.80, p=.370$.

\section{Measures}

Power. Power in the organization was identified by considering criteria used to classify power in natural settings (e.g., Eaton et al., 2009; Weick \& Guinote, 2008): 1) self-assessment of hierarchical level, and 2) information about supervisory responsibilities (having more than one worker under participants' supervision (Van Dijke \& Poppe, 2006). Thus, based on previous work (Weick \& Guinote, 2008), participants were asked to indicate their hierarchical position in the organization. A pyramid represented 
the organizational hierarchy: the top corresponded to the maximum level of power (e.g., head of department/director), and the lower section represented the subordinate level. Individuals who were above the middle of the pyramid were considered to have high-power if they also had supervisory responsibilities. Those who were below the middle were considered to have low-power.

Furthermore, participants with leadership responsibilities, management, and supervisors of more than one employee above the middle of the hierarchical pyramid were considered to have high-power. At the same time, the remaining was classified as low-power. This later classification corresponded $100 \%$ to the self-evaluation made by the participants regarding their hierarchical position. Based on the above criteria, participants were divided into two groups: high-power $(n=24)$ and low-power $(n=26)$.

Decision performance. Decision performance was measured during two distinct periods in the same day (early morning and late afternoon) by two equivalent tasks. Both tasks were adapted from the UTT paradigm using Dijksterhuis' procedures (2004). Specifically, in each task, participants were first presented with information about four apartments. Each apartment was described with 12 attributes, with a total of 48 attributes. The attributes and apartments were created based on a pre-test. Each attribute was presented in the center of the screen for $4 \mathrm{sec}$, while the apartment reference (A, B, C, D) appeared at the top of the screen. Unknown to participants, in both tasks, there was a highly attractive apartment, an indicator of the best decision making (described with eight positive and four negative attributes), and a least attractive apartment with fewer qualities, an indicator of the worst decision (described with four positive and eight negative attributes). The remaining two apartments had medium attractiveness (6 positive and six negative attributes). The presentation order of the 48 items was randomized. The morning and evening tasks were equivalent by following the same criteria but using different attributes to avoid repeating information. At the end of the item presentation, all participants were asked to choose one of the four apartments and evaluate each apartment on a 10-point scale, ranging from 1 (very negative) to 10 (very positive). Thus, both tasks involved immediate decision after the acquisition phase, which is distinct from other conditions of the UTT paradigm that involve conscious deliberation during a period of time before deciding, or making the decision after a distraction phase (as in Smith et al., 2008).

Evaluation of the apartments in each task is displayed in Table 1. As expected, the apartments high in attractiveness (best decision) were positively evaluated by most participants $(60.8 \%)$ in both tasks. In contrast, the apartments with the least attractiveness (worst decision) were evaluated negatively by $80.5 \%$ (task A) and by $56.9 \%$ (task B) of participants. Based on previous procedures (e.g., Dijksterhuis \& Nordgren, 2006; Smith et al., 2008), the quality of the decision-making was calculated by subtracting participants' evaluation of the worst apartment from their evaluation of the best apartment. Higher scores indicate a better decision.

Table 1. Evaluation of the apartments by task

\begin{tabular}{|c|c|c|c|c|}
\hline & \multicolumn{2}{|c|}{ Task A } & \multicolumn{2}{|c|}{ Task B } \\
\hline & $n$ & $\%$ & $n$ & $\%$ \\
\hline \multicolumn{5}{|c|}{ High attractive apartment (best decision) } \\
\hline Negative Evaluation & 20 & 40 & 20 & 40 \\
\hline Positive Evaluation & 30 & 60 & 30 & 60 \\
\hline \multicolumn{5}{|c|}{ Low attractive apartment (worst decision) } \\
\hline Negative Evaluation & 40 & 80 & 28 & 56 \\
\hline Positive Evaluation & 10 & 20 & 22 & 44 \\
\hline \multicolumn{5}{|c|}{ Medium attractive apartment (intermediate decision) } \\
\hline Negative Evaluation & 24 & 48 & 40 & 80 \\
\hline Positive Evaluation & 26 & 52 & 10 & 20 \\
\hline \multicolumn{5}{|c|}{ Medium attractive apartment (intermediate decision) } \\
\hline Negative Evaluation & 34 & 68 & 30 & 60 \\
\hline Positive Evaluation & 16 & 32 & 20 & 40 \\
\hline
\end{tabular}

Note. $N=50$; High attractive apartment = best decision (eight positive + four negative attributes); Low attractive apartment = worst decision (four positive + eight negative attributes); Medium attractive apartments (six positive; six negative attributes); Negative evaluations = participants that responded between 1 (very negative) to 5 (slightly negative); Positive evaluations = participants that responded vary between 6 (slightly positive) to 10 (very positive). 
Subjective fatigue, effort, and alertness. We measured the affective states of alertness, fatigue, and effort by asking participants to indicate while performing each task the extent to which they felt alert ( 3 items: awake, concentrated, in good shape; Cronbach's $\alpha$ of 0.86 in the morning, 0.88 in the afternoon; and 0.78 considering both periods), fatigue ( 2 items: tired, somnolent; $\alpha$ morning $=0.90, \alpha$ afternoon $=0.76 ; \alpha=0.71$ for both periods) and effort (1 item), using a Visual Analog Scale (VAS) with $10 \mathrm{~cm}$, ranging from 0 (very little) to 10 (very much).

Physiological responses. Participants were screen for high blood pressure (BP) by registering their levels of systolic and diastolic BP with a Digital Blood Pressure Monitor (OMRON R3). This system was applied in the upper arm of participants in the morning of the day when the tasks were performed. Eckert et al. (1997) recommended using this non-invasive device for blood pressure self-measurement, given its reliable and accurate values of blood pressure, which satisfied the criteria of the European Standards for Electromechanical Blood Pressure Measuring Systems (prEn 1060-3). Also, skin conductance levels (SCLs) were recorded continuously at both times of the day (morning and afternoon) at baseline (resting period), during the tasks and the decision phases. SCL is a direct measure of sympathetic nervous system activity, providing an optimal index of physiological arousal. It was measured because arousal might affect the decision performance (e.g., Fabbri et al., 2013). To record the SCLs, we used the Affectiva's Q-Sensor 2.0, which had an internal memory card allowing to register data continuously at a sampling rate of $8 \mathrm{~Hz}$. These values were then analyzed off-line using the software Acknowledge 3.9 (Biopac Systems, Inc. 42 Aero Camino Goleta, CA 93117), and mean scores were calculated at each phase. Affectiva's Q-Sensor 2.0 has been previously used in different studies (Baskett et al., 2013; Harley et al., 2015). To consider individual differences, SCL reactivity was calculated by subtracting the baseline value from the values recorded during the decision phase. Thus, our final measure of arousal during the decision-making process corresponds to the physiological reactivity changes in SCLs from baseline.

\section{Procedure}

The study was conducted in a Portuguese pharmaceutical company. After obtaining the company's approval, participants were asked to volunteer for this study and informed that they would be part of a project intended to study housing evaluations. In total, 51 employees were contacted; all accepted to be part of the study and signed an informed consent.

The study was run during two separate days to prevent participants from associating the measurements and thus guessing the study's purpose. Thus, two to three days prior to the decision tasks, participants completed the demographic data, indicating their hierarchy position and their supervised employees. Participants were also asked to not consume caffeine for the 4 hours preceding the decision tasks, as caffeine interferes with cognitive performance, alertness, and arousal (McLellan, Caldwell, \& Lieberman, 2016).

On the second day, we started to place the Digital Blood Pressure Monitor in participants' upper arms to register their BP levels. The electrodes of the physiological device (Q Sensor) were placed in the middle phalanges of the index and the middle finger of the participants' nondominant hand. Skin conductance levels at baseline were collected for two minutes, followed by the instructions for performing the task. After receiving information about all the four apartments' attributes, participants were then asked to decide about the best apartment and evaluate each apartment. Next, they were asked how they felt in terms of alertness, fatigue, and effort while doing the task and making the decision.

The two tasks were performed on the same day by each participant: one task in the early morning (between 8:29 a.m. and 9:46 a.m.) and the other at the end of the working day (between 17:00 and 19:00). The tasks' order was counterbalanced across participants: half performed task\#A in the morning and task\#B in the afternoon, while the other half performed the tasks in the reverse order. At the end, participants were debriefed, thanked, and asked not to share information with colleagues. Overall, each task took about 15 to 20 minutes to complete.

\section{RESULTS}

\section{Decision, subjective states (alertness, fatigue, effort), and physiological arousal, as a function of} power and time-of-day

To analyze whether power is related to our outcome variables (quality of the decision making, perceived alertness, fatigue, and effort, and physiological arousal) as a function of the time-of-day in which the decision task was performed, five analysis of covariance (ANCOVA) 2 (power: low, high) X 2 (time-of-day: morning, afternoon) were conducted for each outcome, having power as a between-subject, and time-ofday as a within-subject factor. Age and diastolic BP were included as covariates to account for the 
differences between high and low power participants in these variables. Means, standard deviations, and main outcomes of the ANCOVAs are presented in Table 2.

Table2. Means and standard deviations of decision, subjective and physiological responses for the overall sample and as a function of power and time-of-day (controlling for age and diastolic blood pressure)

\begin{tabular}{|c|c|c|c|c|c|c|c|c|c|}
\hline & \multicolumn{2}{|c|}{$\begin{array}{l}\text { Overall } \\
(N=50)\end{array}$} & \multicolumn{2}{|c|}{$\begin{array}{c}\text { Low-Power } \\
(n=26)\end{array}$} & \multicolumn{2}{|c|}{$\begin{array}{c}\text { High-Power } \\
(\mathrm{n}=24)\end{array}$} & \multirow[t]{2}{*}{$F_{\text {Power }}$} & \multirow[t]{2}{*}{$F_{\text {Time }}$} & \multirow[t]{2}{*}{$F_{\text {PowerxTime }}$} \\
\hline & $M$ & $S D$ & $M$ & $S D$ & $M$ & $S D$ & & & \\
\hline Decision & & & & & & & $8.22^{*}$ & 0.18 & 0.56 \\
\hline Morning & 1.12 & 2.48 & 0.77 & 2.49 & 1.50 & 2.47 & & & \\
\hline Afternoon & 1.14 & 2.69 & 0.27 & 2.57 & 2.08 & 2.54 & & & \\
\hline Fatigue & & & & & & & 1.94 & 0.004 & 0.22 \\
\hline Morning & 2.74 & 2.35 & 3.24 & 2.52 & 2.19 & 2.08 & & & \\
\hline Afternoon & 2.93 & 2.11 & 3.23 & 2.16 & 2.61 & 2.05 & & & \\
\hline Alertness & & & & & & & 2.16 & 0.53 & 0.07 \\
\hline Morning & 6.28 & 2.19 & 5.91 & 2.42 & 6.68 & 1.89 & & & \\
\hline Afternoon & 6.87 & 1.81 & 6.69 & 1.83 & 7.06 & 1.81 & & & \\
\hline Effort & & & & & & & 1.22 & 0.34 & 0.80 \\
\hline Morning & 4.16 & 2.84 & 3.63 & 3.00 & 4.73 & 2.59 & & & \\
\hline Afternoon & 3.86 & 2.86 & 3.66 & 2.96 & 4.08 & 2.79 & & & \\
\hline \multicolumn{2}{|c|}{$\Delta$ Skin conductance } & & & & & & 0.93 & 0.16 & 0.04 \\
\hline Morning & 0.39 & 0.60 & 0.35 & 0.68 & 0.41 & 0.55 & & & \\
\hline Afternoon & 0.37 & 0.70 & 0.28 & 0.67 & 0.45 & 0.74 & & & \\
\hline
\end{tabular}

Note. ${ }^{*} p<.01$

Regarding the decision making, results showed a significant main effect of power, $F(1,46)=8.22, p=$ $.006, \eta p^{2}=.152$, indicating that high-power participants made better decisions $(M=1.18)$ than low-power participants $(M=1.14)$. However, there was no statistically significant effect of time-of-day, nor was there an interaction between power and time-of-day; no significant effects were found for the covariates, all $F<$ 1. These results indicate that the effect of power on decision occurred regardless of the time-of-day in which the decision task was performed.

As can be seen in Table 2, results of the ANCOVAs for the subjective affective states (alertness, fatigue, effort), and physiological arousal (SCL changes from baseline) have also indicated no statistically main effects and interactions between power and time-of-day, neither any effects of the covariates $(p s>$ $.10)$.

\section{Predictors of Decision}

Given the null effects of the time-of-day in the outcomes, the results obtained for each outcome variable were averaged. Because no effects of power were found on skin conductance changes and the subjective reports of alertness, fatigue, and effort, the mediation analyses were not conducted. Instead, a hierarchical multiple regression (HMR) was performed to examine the amount of variance in decision-making that could be explained by power after accounting for participants' subjective and physiological responses related to the completion of the task. Participant's physiological arousal changes during the task's completion, and subjective reports of fatigue, alertness, and effort, were entered at step 1, and power entered at step 2 . The collinearity tolerance results were all higher than .74, and the variance inflation factors were below 1.4, indicating that there were no multicollinearity problems to conduct the HMR.

As shown in Table 3, the subjective and physiological responses accounted for $24.3 \%$ of the decision, with a statistical significant contribution, $F(4,42)=3.37, p=.018$. On examination of these specific results, we found that higher perceived alertness $(\beta=.47, t=1.19, p=.003$, [95\% CI: .20, .91]) and effort while doing the task $(\beta=.33, t=2.21, p=.021 ; 95 \%$ CI $[.02, .46])$ significantly predicted a better decision. Also, the overall model for the second step in which power was added was statistically significant, $F(5,41)=$ $3.73, p=.007$, indicating that power explained an additional $7 \%$ of the variance in decision, above and beyond the variables that were added in step 1. Also, besides power, perceived alertness continued to be a significant predictor of decision while performing the decision task. 
Table3. Hierarchical multiple regression results of predictors of decision

\begin{tabular}{lcccccc}
\hline \multirow{2}{*}{ Predictors } & \multicolumn{3}{c}{ Step 1 } & \multicolumn{3}{c}{ Step 2 } \\
\cline { 2 - 7 } & $\mathrm{B}(S E)$ & $\beta$ & $t$ & $\mathrm{~B}(S E)$ & $\beta$ & $t$ \\
\hline$\Delta$ Skin conductance & $0.78(0.56)$ & 0.20 & 1.41 & $0.81(0.54)$ & 0.20 & 1.50 \\
Effort & $0.24(0.11)$ & 0.33 & $2.21^{*}$ & $0.18(0.11)$ & 0.24 & 1.60 \\
Fatigue & $0.21(0.15)$ & 0.20 & 1.41 & $0.27(0.15)$ & 0.27 & 1.88 \\
Alertness & $0.55(0.17)$ & 0.47 & $3.19^{* *}$ & $0.48(0.17)$ & 0.41 & $2.79^{* *}$ \\
\hline Power & & & & $-1.02(0.50)$ & -0.29 & $-2.04^{*}$ \\
\hline$R^{2}$ & .24 & & & .31 & & \\
$\Delta R^{2}$ & -- & & & & & \\
\hline Note. ${ }^{*} p<.05,{ }^{* *} p<.01$ & & & & & &
\end{tabular}

\section{DISCUSSION}

The last two decades of experimental research on social power has shown that being temporarily in a powerful position has advantages, whereas being powerless has disadvantages for the speed and often for the quality of decision making (see Guinote, 2017; Smith et al., 2008). Here we showed that occupying different hierarchical positions in the organization also predicted the quality of decision making. Participants who had hierarchical organizational power made better apartment decisions compared to their subordinate counterparts.

One question that arises is, why do people in such powerful positions make better decisions than powerless people? Our analyses excluded several factors. First, we considered several measures that are often related to performance in decision-making tasks, such as fatigue, effort, alertness, and physiological arousal (e.g., Fabbri et al., 2013; Wright \& Kirby, 2001). Although we found that high alertness and effort for doing the task were predictors of a better decision, no differences were found in these variables between individuals with high and lower power in the organization, which indicates that these factors have not contributed to explaining the differences in decision-making as a function of organizational power.

Nevertheless, it is noteworthy that power was the main predictor of decision quality over and above these subjective and physiological states, and that alertness remained an important contributor to decision quality. We did not find support for the effect of time-of-day or that power could affect employers' decisions differently as a function of the time-of-day on subjective states and physiological arousal. The role of timeof-day on decision making has been poorly investigated, and the results also seem to depend on the type of decision-making tasks (e.g., Ingram et al., 2016). Our results suggest a possible lack of support to the relevance of time-of-day for this task. However, it would be important to consider the type of resources and the level of difficulty the tasks require to understand the conditions under which the effect of power prevails. Also, the time-of-day in which the tasks were performed could not have been the best to test their role in decision performance. We selected the opposite time-of-day by considering our participants' working hours in the organization involved in this study. However, we should consider that many organizations require individuals to work in non-standard working hours, including engagement in night work, sometimes involving night shifts, with different implications to the quality of the decisions and the wellbeing (for a review see Costa, 2010).

Experimental findings suggest that power differences are triggered by the beneficial consequences of feeling in control and the disadvantages of lacking control for one's ability to differentiate between relevant and irrelevant information (Guinote, 2007a, 2017; Smith et al., 2008). As our results show, people who had hierarchical organizational power made more differentiated evaluations of the apartments, with more positive evaluations of the best apartment and worst evaluations of the worst apartment than powerless individuals who evaluated the apartments more evenly. Thus, organizational power holders were better able to differentiate between positive and negative apartment attributes than powerless individuals. These differences could be linked to differences in sustained attention, as participants were gathering a relatively large amount of information about the apartments. They could be driven by memory differences or by the weight given to multiple attributes when making decisions. Naturally occurring power in the organization and temporarily afforded power seem to have similar effects on decision making. This finding is important because most recent socio-cognitive research on social power is based on experimental methodology. Thereby participants have temporary power over another or have a power (vs. control or powerless mindset).

There are several implications of the effects obtained. On the one hand, people in authority positions have the responsibility to make decisions with large consequences. They are expected to be decisive and 
make fast decisions. Thus, a power advantage in decision making helps carry out these responsibilities efficiently. On the other hand, lacking power can be detrimental for decision-making, which has negative personal and business implications. The negative effects of lacking power for the individual are well document (see Guinote \& Lammers, 2017). In organizational contexts, feeling deprived of personal control is detrimental to health and wellbeing (Marmot et al., 1991). Employees who experience high demands but have low control over decisions and the ways they work are at higher risk of coronary heart diseases than those who have more control (Kivimäki et al., 2012). Our research demonstrates one more negative correlate of being powerless - the extent to which individuals make the right decisions.

Noteworthy is that in our study, it is difficult to set apart whether the differences obtained are driven by having power or lacking power. Even though we considered a range of employees, participants were not assigned either to a powerful or a powerless condition. A future study with a larger sample may inform us about subordinate employees' predicament across levels of the organization, including those who lack power but have reasonable high levels of control.

We should consider other limitations in the present study. The fact that power holders made better decisions in the present task does not mean that they are better decision-makers in other domains. Power holders are often socially inattentive, and in some contexts, they are overconfident (Fast et al., 2012; see also Guinote, 2017). In contrast, powerless individuals pay attention to detail and may deliberate more before making decisions. Thus, in situations such as the ones we are describing, we would expect powerful people not to be better decision-makers than powerless people.

We should also consider that the study was conducted with a small convenience sample of participants working in a single organization. Most participants have high education levels, which precludes us from generalizing the results to other organizational contexts.

Several studies also indicate that performance in a task can depend on the level of motivation of the performer (e.g., Hayashi et al., 1998; Hines, 2004). Our study has used a task that might have been perceived as irrelevant or uninteresting for the participants, which may have reduced the level of implication and/or motivation for making the right decision. Future studies should also test other decision modes that can be used with the UTT paradigm (e.g., deliberation, distraction) for complex decisions in other natural environments, and use other tasks that require another type of decisions (e.g., risk, moral), as well as tasks that consider the levels of motivation of participants.

In summary, we found that power, based on the position that individuals occupy in the organization and supervision responsibilities, consistently affected how they made decisions, measured at different times of the day. Power holders made more accurate evaluations of apartments that varied in quality.

\section{REFERENCES}

Abadie, M., Villejoubert, G., Waroquier, L., \& Vallée-Tourangeau (2013). The interplay between presentation material and decision mode for complex choice preferences. Journal of Cognitive Psychology, 25, 682691. https://doi.org/10.1080/20445911.2013.786721

Anderson, C., \& Kilduff, G. J. (2009). Why do dominant personalities attain influence in face-to-face groups? The competence-signaling effects of trait dominance. Journal of Personality and Social Psychology, 96(2): 491-503. https://doi.org/10.1037/a0014201

Baddeley, A. D. (1996). The concept of working memory. In S. Gathercole (Ed.), Models of short-term memory (pp. 1-28). Lawrence Erlbaum Associates.

Barbosa, F. F., Albuquerque, F.S. (2008). Effect of the time-of-day of training on explicit memory. Brazilian Journal of Medical and Biological Research, 41, 477-481. https://doi.org/10.1590/S0100879X2008005000023

Baskett, P., Shang, Y., Patterson, M. V., \& Trull, T. (2013). Towards a system for body-area sensing and detection of alcohol craving and mood dysregulation. Paper presented the 2013 IEEE Consumer Communications and Networking 875-876. https://doi.org/10.1109/CCNC.2013.6488575

Cai, R. A., \& Guinote, A. (2017). Doing many things at a time: Lack of power decreases the ability to multitask. British Journal of Social Psychology, 56(3), 475-492. https://doi.org/10.1111/bjso.12190

Costa, G. (2010). Shift work and health: current problems and preventive actions. Safety and Health at Work, 1(2), 112-123. https://doi.org/10.5491/SHAW.2010.1.2.112

Craig, A., Davies, D., \& Matthews, G. (1987). Diurnal variation, task characteristics, and vigilance performance. Human Factors, 29(6), 675-684. https://doi.org/10.1177/001872088702900607

DeWall, C. N., Baumeister, R. F., Mead, N. L., \& Vohs, K. D. (2011). How leaders self-regulate their task performance: Evidence that power promotes diligence, depletion, and disdain. Journal of Personality and Social Psychology, 100(1), 47-65. https://doi.org/10.1037/a0020932 
Dijk, D. J., Duffy, J. F., \& Czeisler, C. A. (1992). Circadian and sleep/wake dependent aspects of subjective alertness and cognitive performance. Journal of sleep research, 1(2), 112-117.

Dijksterhuis, A. (2004). Think different: The merits of unconscious thought in preference development and decision making. Journal of Personality and Social Psychology, 87, 586-598. https://doi.org/10.1037/0022-3514.87.5.586

Eaton, A. A., Visser, P. S., Krosnick, J. A., \& Anand, S. (2009). Social power and attitude strength over the life course. Personality and Social Psychology Bulletin, 35(12), 1646-1660. https://doi.org/10.1177/0146167209349114

Eckert, S., Gleichmann, U., Zagorski, O., \& Klapp, A. (1997). Validation of the OMRON R3 blood pressure selfmeasuring device through simultaneous comparative invasive measurements according to protocol 58130 of the German Institute for Validation. Blood Pressure Monitoring, 2(4), 189-192.

Fabbri, M., Mencarelli, C., Adan, A., \& Natale, V. (2013). Time-of-day and circadian typology on memory $\begin{array}{lllll}\text { retrieval. Biological Rhythm } & \text { Research, } & \text { 44(1), } & \text { 125-142. }\end{array}$ https://doi.org/10.1080/09291016.2012.656244

Fast, N. J., Sivanathan, N., Mayer, N. D., \& Galinsky, A. D. (2012). Power and overconfident decision-making. Organizational Behavior and Human Decision Processes, 117(2), 249-260. https://doi.org/10.1016/j.obhdp.2011.11.009

Fiske, S. T. (2009). Social beings: Core motives in social psychology. John Wiley \& Sons.

Fiske, S. T. (2010). Interpersonal stratification: Status, power, and subordination. In S. T. Fiske, D. T. Gilbert, \& G. Lindzey (Eds.), Handbook of Social Psychology (5th ed, pp. 941-982). John Wiley \& Sons Inc.

Fiske, S. T., \& Dépret, E. (1996). Control, interdependence and power: Understanding social cognition in its social context. European Review of Social Psychology, 7(1), 31-61. https://doi.org/10.1080/14792779443000094

Guinote, A. (2007a). Power affects basic cognition: Increased attentional inhibition and flexibility. Journal of Experimental Social Psychology, 43(5), 685-697. https://doi.org/10.1016/j.jesp.2006.06.008

Guinote, A. (2007b). Power and goal pursuit. Personality and Social Psychology Bulletin, 33(8), 1076-1087. https://doi.org/10.1177/0146167207301011

Guinote, A. (2017). How power affects people: Activating, wanting, and goal seeking. Annual Review of Psychology, 68, 353-381. https://doi.org/10.1146/annurev-psych-010416-044153

Guinote, A., \& Chen, S. (2018). Power as active self: From acquisition to the expression and use of power. In K. Deaux \& M. Snyder (Eds.), Oxford Handbook of Personality and Social Psychology (2nd ed, pp. 645671). Oxford University Press.

Guinote, A., \& Lammers, J. (2017). Accentuation of tending and befriending among the powerless. In M. Bukowski, I Fritsche, A. Guinote, M. Kofta, Coping with lack of control in a social world (pp. 185-202). Routledge.

Harada, T., Bridge, D. J., \& Chiao, J. Y. (2013). Dynamic social power modulates neural basis of math calculation. Frontiers in Human Neuroscience, 6(350), 115-127. https://doi.org/10.3389/Fnhum.2012.00350

Harley, J. M., Bouchet, F., Hussain, M. S., Azevedo, R., \& Calvo, R. (2015). A multi-componential analysis of emotions during complex learning with an intelligent multi-agent system. Computers in Human Behavior, 48, 615-625. https://doi.org/10.1016/j.chb.2015.02.013

Hayashi, M., Minami, S., \& Hori, T. (1998). Masking effect of motivation on ultradian rhythm. Perceptual and Motor Skills, 86(1), 127-136. https://doi.org/10.2466/pms.1998.86.1.127

Hayes, A. F., \& Matthes, J. (2009). Computational procedures for probing interactions in OLS and logistic regression: SPSS and SAS implementations. Behavior Research Methods, 41(3), 924-936. https://doi.org/10.3758/BRM.41.3.924

Ingram, K. K., Ay, A., Bin Kwon, S., Woods, K., Escobar, S., Gordon, M., . . Jain, K. (2016). Molecular insights into chronotype and time-of-day effects on decision-making. Scientific Reports, 6, 1-9. https://doi.org/10.1038/srep29392

Judge, T. A., Colbert, A. E., \& Ilies, R. (2004). Intelligence and leadership: A quantitative review and test of theoretical propositions. Journal of Applied Psychology, 89(3), 542-552. https://doi.org/10.1037/0021-9010.89.3.542

Kivimäki, M., Nyberg, S. T., Batty, G. D., Fransson, E. I., Heikkilä, K., Alfredsson, L., et al. \& Clays, E. (2012). Job strain as a risk factor for coronary heart disease: A collaborative meta-analysis of individual participant data. The Lancet, 380(9852), 1491-1497. https://doi.org/10.1016/S01406736(12)60994-5

Kouchaki., M. \& Smith, I. H. (2014). The morning morality effect: The influence of time of day on unethical behavior. Psychological Science, 25, 95-102. https://doi.org/10.1177/0956797613498099. 
Kronholm, E., Hyppa, M. T., Jula, A., \& Toikka, T. (1996). Electrodermal lability and hypertension. International Journal of Psychophysiology, 23(1-2), 129-136. doi: 10.1016/0167-8760(96)00044-X

Lammers, J., Dubois, D., Rucker, D. D., \& Galinsky, A. D. (2013). Power gets the job: Priming power improves interview outcomes. Journal of Experimental Social Psychology, 49(4), 776-779. https://doi.org/10.1016/j.jesp.2013.02.008

Lammers, J., Stoker, J. I., Rink, F., \& Galinsky, A. D. (2016). To have control over or to be free from others? The desire for power reflects a need for autonomy. Personality and Social Psychology Bulletin, 42(4), 498-512. https://doi.org/10.1177/0146167216634064

Magee, J. C., Galinsky, A. D., \& Gruenfeld, D. H. (2007). Power, propensity to negotiate, and moving first in competitive interactions. Personality and Social Psychology Bulletin, 33(2), 200-212. https://doi.org/10.1177/0146167206294413

Major, B. (1994). From social inequality to personal entitlement: The role of social comparisons, legitimacy appraisals, and group membership. In M. Zanna (Ed.), Advances in Experimental Social Psychology (Vol. 26, pp. 293-355). Academic Press.

Marmot, M. G., Stansfeld, S., Patel, C., North, F., Head, J., White, I., ... \& Smith, G. D. (1991). Health inequalities among British civil servants: The Whitehall II study. The Lancet, 337(8754), 1387-1393. https://doi.org/10.1016/0140-6736(91)93068-K

McLellan, T. M., Caldwell, J. A., \& Lieberman, H. R. (2016). A review of caffeine's effects on cognitive, physical and occupational performance. Neuroscience \& Biobehavioral Reviews, 71, 294-312. https://doi.org/10.1016/j.neubiorev.2016.09.001

Monteiro, M. B. (2003). Assimetria entre recursos positivos e negativos em relações intergrupais: Retóricas da discriminação [Asymmetry between positive and negative resources in intergroup relations: Rhetorics of discrimination]. In L. Lima, P. Castro, M. Garrido, Temas e debates em psicologia social (pp. 73-92). Livros Horizonte.

Monteiro, M. B., França, D. X., \& Rodrigues, R. (2009). The development of intergroup bias in childhood: How social norms can shape children's racial behaviours. International Journal of Psychology, 44(1), 29-39. https://doi.org/10.1080/00207590802057910

Nissan, T., Shapira, O., \& Liberman, N. (2015). Effects of power on mental rotation and emotion recognition in women. Personality and Social Psychology Bulletin, 41(10), 1425-1437. https://doi.org/10.1177/0146167215598748

Oken, B. S., Salinsky, M. C., \& Elsas, S. M. (2006). Vigilance, alertness, or sustained attention: Physiological basis and measurement. Clinical Neurophysiology, 117(9), 1885-1901. https://doi.org/10.1016/j.clinph.2006.01.017

Sachdev, I., \& Bourhis, R. Y. (1991). Power and status differentials in minority and majority group relations. European Journal of Social Psychology, 21, 1-24. https://doi.org/10.1002/ejsp.2420210102

Scheepers, D., de Wit, F., Ellemers, N., \& Sassenberg, K. (2012). Social power makes the heart work more efficiently: Evidence from cardiovascular markers of challenge and threat. Journal of Experimental Social Psychology, 48(1), 371-374. https://doi.org/10.1016/j.jesp.2011.06.014

Smith, P. K., Jostmann, N. B., Galinsky, A. D., \& van Dijk, W. W. (2008). Lacking power impairs executive functions. Psychological Science, 19(5), 441-447. doi: 10.1111/j.1467-9280.2008.02107.x

Smith, P. K., Dijksterhuis, A., \& Wigboldus, D. H. J. (2008). Powerful people make good decisions even when they consciously think. Psychological Science, 19(12), 1258-1259. https://doi.org/10.1111/j.14679280.2008.02207.x

Smith, P. K., \& Trope, Y. (2006). You focus on the forest when you're in charge of the trees: Power priming and abstract information processing. Journal of Personality and Social Psychology, 90(4), 578-596. https://doi.org/10.1037/0022-3514.90.4.578

Taylor, Y., Merat, N., \& Jamson, S. (2018). The effects of fatigue on cognitive performance in police officers and staff during a forward rotating shift pattern. Safety and Health at Work, 10(1), 67-74. https://doi.org/10.1016/j.shaw.2018.08.003

Testu, F., \& Clarisse, R. (1999). Time-of-day and day-of-week effects on mnemonic performance. Chronobiology International, 16(4), 491-503. https://doi.org/10.3109/07420529908998723

Van Dijke, M., \& Poppe, M. (2006). Striving for personal power as a basis for social power dynamics. European Journal of Social Psychology, 36(4), 537-556. https://doi.org/1467-9280.2008.02207.x

Van Loo, K. J., \& Rydell, R. J. (2013). On the experience of feeling powerful: Perceived power moderates the effect of stereotype threat on women's math performance. Personality and Social Psychology Bulletin, 39(3), 387-400. https://doi.org/10.1177/0146167212475320

Weick, M., \& Guinote, A. (2008). When subjective experiences matter: Power increases reliance on the ease of retrieval. Journal of Personality and Social Psychology, 94(6), 956-970. https://doi.org/10.1037/0022-3514.94.6.956 
Wojciszke, B., \& Struzynska-Kujalowicz, A. (2007). Power influences self-esteem. Social Cognition, 25(4), 472-494. https://doi.org/10.1521/soco.2007.25.4.472

Wright, R. A., \& Kirby, L. D. (2001). Effort determination of cardiovascular response: An integrative analysis with applications in social psychology. Advances in Experimental Social Psychology, 33, 255-307. https://doi.org/10.1016/S0065-2601(01)80007-1

$\begin{array}{lr}\text { Historial do } & \text { artigo } \\ \text { Recebido } & 04 / 2018 \\ \text { Aceite } & 11 / 2019 \\ \text { Publicado } & 12 / 2020\end{array}$


Power and decision making 